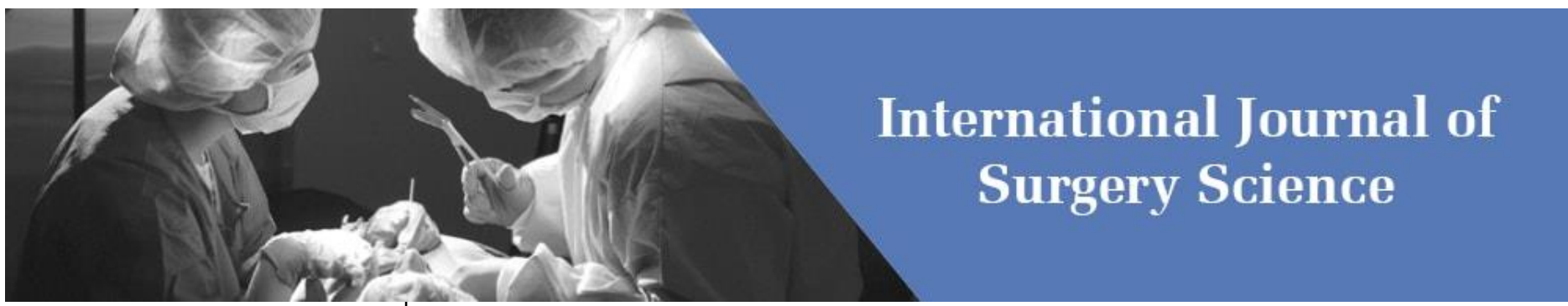

E-ISSN: 2616-3470

P-ISSN: 2616-3462

(C) Surgery Science

www.surgeryscience.com

2021; 5(2): 141-144

Received: 17-02-2021

Accepted: 30-03-2021

Deepak Kumar Bhojwani

Assistant Professor, Chirayu

Medical College \& Hospital,

Bhopal, Madhya Pradesh, India

Kiran Dodani

Professor and HOD, Department of Periodontology, RKDF Dental College and Research Centre,

Bhopal, Madhya Pradesh, India

\section{A prospective randomised trial comparing the outcome of laparoscopic hernioplasty to Lichtenstein's open mesh repair}

\section{Deepak Kumar Bhojwani and Kiran Dodani}

DOI: https://doi.org/10.33545/surgery.2021.v5.i2c.677

Abstract

Aim: To evaluate the comparative outcome of Laparoscopic technique versus open repair for inguinal hernia.

Methods: A randomized prospective study was conducted in the Department of General Surgery to compare laparoscopic hernioplasty and Lichtenstein's open mesh repair. The study consisted of 100 subjects with unilateral or bilateral inguinal hernia and they were randomly allocated into either group. Various parameters like duration of surgery, intra and post-operative complications, post-operative pain, recurrence, stay in the hospital and resumption of daily activities were compared.

Results: Out of the 100 patients, 24 had bilateral inguinal hernia and the rest 76 had unilateral. 14 patients with bilateral hernia underwent laparoscopic repair and 10 underwent open mesh repair. 36 patients with unilateral hernia underwent laparoscopic hernioplasty and 40 underwent open mesh repair. The mean operative time for unilateral open hernioplasty was 46.86 mins and bilateral was 91.10 mins whereas, for unilateral laparoscopic hernioplasty it was $65.18 \mathrm{mins}$ and bilateral was 120.55 mins post-operative complications, like wound infection was noted in $14 \%$ (7 out of 50 patients) and $18 \%$ had seroma formation (9 out of 50 patients) in the open hernioplasty group. In laparoscopic hernioplasty group, $2 \%$ (1) had wound infection but, seroma formation was noted in $12 \%$ ( 6 out of 50 patients). Urinary retention was noted $20 \%$ of open hernioplasty group (10 out of 50) and 6\% of laparoscopic hernioplasty group (3 out of 50 patients).

Conclusion: Laparoscopic hernioplasty is more beneficial than Lichtenstein's open hernia mesh repair as it is safer, with faster recovery, lesser post-operative complications and reduced morbidity.

Keywords: Inguinal hernia, Lichtenstein's repair, Laparoscopic hernioplasty

\section{Introduction}

Inguinal hernia repair is one of the most common procedures undertaken by surgeons all over the world. The treatment of this common problem has progressed from pure tissue repairs to prosthetic repairs and, most recently, laparoscopic surgery. Lichtenstein's tension-free inguinal hernioplasty with a prosthetic mesh is the preferred method for open inguinal hernia repair ${ }^{[1]}$. As opposed to tissue replacements, where the recurrence rate can be as high as $15 \%$, the recurrence rate of skilled hands is less than $1 \%{ }^{[2]}$. Postoperative morbidity is minimal, and healing is swift.

In today's surgical world, laparoscopy has achieved universal recognition. The benefits and effectiveness of laparoscopic cholecystectomy over open cholecystectomy have been well known, and it has now established itself as the gold standard for gallstone disease control [3]. Several research have demonstrated that laparoscopic hernioplasty (LSH) is superior to open hernioplasty $(\mathrm{OH})$ in terms of postoperative pain and morbidity, wound complications, postoperative nausea, early return to operation and function and improved cosmetic performance [4-6]. But it had some limitations like twice longer operative time, longer learning curve, higher hospital cost, a potential for serious life threatening accidents and a higher recurrence rate especially immediately in early postoperative period as compared with open surgery.

Trans abdominal preperitoneal (TAPP) and totally extra peritoneal (TEP) mesh repair are two options for laparoscopic hernioplasty. TAPP entails penetrating the abdominal cavity and viewing the sac and contents directly before placing the mesh pre-peritoneally. On the other hand, Lichtenstein's open mesh repair is the gold standard for all open techniques ${ }^{[7,8]}$.
Corresponding Author: Assistant Professor, Chirayu Medical College \& Hospital,

Bhopal, Madhya Pradesh, India 
The aim of this research is to compare the outcomes of laparoscopic (TAPP mesh repair) and open hernia repair in terms of surgical time, intraoperative and postoperative complications, postoperative discomfort, recurrence, hospital stay, and return to normal activities.

\section{Material and methods}

A randomized study was conducted in the Department of General Surgery, after taking the approval of the protocol review committee and institutional ethics committee.

After taking informed consent detailed history was taken from the patient or the relatives if the patient was not in good condition.

\section{Methodology}

Both patients were informed about the procedure's technique, costs, advantages, outcomes, and related complications. A total of 100 patients with inguinal hernias, both unilateral and bilateral, were operated on. The sample size was calculated using data from a previous analysis by Rathod CM et al. ${ }^{[9]}$. Adults over the age of 18 who had a unilateral or bilateral main inguinal hernia were included in the study. Patients with complex hernias (irreducible, obstructed, strangulated), large sacs, and chronic hernias were omitted from the study. Also excluded were those unfit for general anaesthesia, laparoscopy or pneumoperitoneum i.e. those with cardiac diseases (MI, IHD), respiratory diseases (chronic asthma, COPD), renal or hepatic diseases, bleeding disorders etc. were excluded from the study.

\section{Groups}

The patients were grouped into two classes of 50 and randomly assigned to either laparoscopic or open hernioplasty using a computer random sequence generator in a 1:1 ratio. A specific identification number was assigned to each patient. At the baseline visit, the prescribing surgeon reported demographic records, medical history, concomitant prescriptions, and physical inspection in the research preform, and related investigations such as full blood count and ultrasound abdomen and pelvis were performed.

Patients in group A had laparoscopic hernioplasty, and those in group B had open hernia mesh repairs. Under spinal anaesthesia, Lichtenstein's tension-free repair was performed for open hernioplasty. Under general anaesthesia, the TAPP mesh repair procedure was used to do the laparoscopic repair. Operation time, pre-and post-operative complications, post-operative pain, recurrence, length of stay in the hospital, and time to recover routine everyday activities after surgery were all evaluated. The data was interpreted as a mean of standard deviation. The tactile analogue pain scale was used to measure post-operative pain. The mean of two groups was compared using the test, and $\mathrm{p} \leq 0.05$ was considered important.

\section{Results}

Table 1: Gender and age distribution of patients

\begin{tabular}{|c|c|}
\hline Gender & $\mathbf{N = 1 0 0}$ \\
\hline Male & 88 \\
\hline Female & 12 \\
\hline Mean age for laparoscopic technique & 51.14 \\
\hline Mean age for laparoscopic technique & 52.87 \\
\hline
\end{tabular}

Table 2: Type of hernia

\begin{tabular}{|c|c|c|c|}
\hline Type & $\begin{array}{c}\text { Unilateral } \\
\text { inguinal hernia }\end{array}$ & $\begin{array}{c}\text { Bilateral } \\
\text { inguinal hernia }\end{array}$ & Total \\
\hline $\begin{array}{c}\text { Laparoscopic } \\
\text { hernioplasty }\end{array}$ & 36 & 14 & 50 \\
\hline Open Hernioplasty & 40 & 10 & 50 \\
\hline Total & 76 & 24 & 100 \\
\hline
\end{tabular}

Table 3: Mean duration of surgery

\begin{tabular}{|c|c|c|}
\hline Type & $\begin{array}{c}\text { Unilateral inguinal } \\
\text { hernia }\end{array}$ & $\begin{array}{c}\text { bilateral inguinal } \\
\text { hernia }\end{array}$ \\
\hline $\begin{array}{c}\text { Laparoscopic } \\
\text { hernioplasty }\end{array}$ & $65.18 \mathrm{~min}$ & $120.55 \mathrm{~min}$ \\
\hline Open Hernioplasty & $46.86 \mathrm{~min}$ & $91.10 \mathrm{~min}$ \\
\hline
\end{tabular}

Table 4: Post-operative complications

\begin{tabular}{|c|c|c|c|}
\hline Type & $\begin{array}{c}\text { Wound } \\
\text { infection }\end{array}$ & $\begin{array}{c}\text { Seroma } \\
\text { formation }\end{array}$ & $\begin{array}{c}\text { Urinary } \\
\text { retention }\end{array}$ \\
\hline $\begin{array}{c}\text { Laparoscopic } \\
\text { hernioplasty }\end{array}$ & 1 & 6 & 3 \\
\hline Open Hernioplasty & 7 & 9 & 10 \\
\hline
\end{tabular}

Table 5: Post-operative pain score

\begin{tabular}{|c|c|c|c|}
\hline \multirow{2}{*}{ Type } & \multicolumn{3}{|c|}{ Visual analogue scale score } \\
\cline { 2 - 4 } & POD 0 & POD 3 & POD 7 \\
\hline Laparoscopic hernioplasty & 5.8 & 4.2 & 1.7 \\
\hline Open Hernioplasty & 6.6 & 5.0 & 2.9 \\
\hline
\end{tabular}

Table 6: Mean duration of hospital stay

\begin{tabular}{|c|c|}
\hline Type & No of days \\
\hline Laparoscopic hernioplasty & 4 \\
\hline Open Hernioplasty & 7 \\
\hline
\end{tabular}

Table 7: Time taken to resume daily activities

\begin{tabular}{|c|c|}
\hline Type & No. of days \\
\hline Laparoscopic hernioplasty & $\mathbf{5 . 1}$ \\
\hline Open Hernioplasty & $\mathbf{8 . 4}$ \\
\hline
\end{tabular}

\section{Discussion}

This study compares the outcomes of TAPP laparoscopic hernioplasty with Lichtenstein's open mesh repair in patients with unilateral and bilateral inguinal hernias. In our study, the average age of the patients in both groups was similar. Previously, Hamza et al. and Sudarshan PB et al. ${ }^{[10,11]}$ had reported similar results. Unlike previous studies, such as Sudarshan PB et al. ${ }^{[11]}$, which only looked at unilateral hernias, ours looked at patients with both unilateral and bilateral hernias. There were 76 unilateral inguinal hernia cases and 24 bilateral inguinal hernia cases in our study. 14 out of those with bilateral underwent laparoscopic hernioplasty and 10 open mesh repairs. The mean operative time for unilateral open hernioplasty was 46.86 mins and bilateral was 91.10 mins whereas, for unilateral laparoscopic hernioplasty it was 65.18 mins and bilateral was 120.55 mins. Rathod CM et al. and Hamza et al. reported similar results where laparoscopic mesh repair took longer than Lichtenstein's open mesh repair ${ }^{[9,10]}$. In our study, we did not 
record any intra operative complications like injury to spermatic cord, vessels and viscera in both the groups. Sudarshan PB et al. and Hamza et al. had reported similar results in their studies [10, 11]. Whereas, Neumayer L et al. had reported that $4.8 \%$ of laparoscopy patients and $1.9 \%$ of open repair patients had intra operative complications ${ }^{[12]}$. McCormack et al. conducted a meta-analysis and noted that operative complications such as visceral, especially bladder and vascular injuries were higher in laparoscopic technique ${ }^{[13]}$. Several other older studies had observed higher complications with laparoscopic surgeries ${ }^{[14-20]}$. Post-operative complications, like wound infection was noted in $14 \%$ ( 7 out of 50 patients) and $18 \%$ had seroma formation ( 9 out of 50 patients) in the open hernioplasty group. In laparoscopic hernioplasty group, $2 \%$ (1) had wound infection but, seroma formation was noted in $12 \%$ (6 out of 50 patients). Urinary retention was noted $20 \%$ of open hernioplasty group (10 out of 50 ) and $6 \%$ of laparoscopic hernioplasty group (3 out of 50 patients). Sudarshan PB et al. had reported similar results with respect to seroma formation and urinary retention ${ }^{[11]}$.

On comparing the mean pain score of two groups, POD 0 score was not statistically significant ( $p$ value 0.1188 ) but the pain score of POD-3 (p=0.0145) and POD-7 (p<0.0001) were statistically significant. Hence, laparoscopic hernia had significantly lesser pain score on postoperative day 3 and 7 . Sudarshan PB et al. had reported similar results in their study [11].

The mean duration of hospital stays showed a statistically significant difference of 4 days for laparoscopic surgery and 7 days for open hernioplasty $(\mathrm{p}<0.0001)$. Sudarshan PB et al. reported that in laparoscopic surgeries it was 3.07 days and 7 . 8days post open surgery ${ }^{[11]}$. Singh V et al. on the contrary reports a stay of 1.8 days after open surgery and 3.5 days after laparoscopic surgery. The longer duration of stay in laparoscopic surgery was due to complications seen post operatively ${ }^{[21]}$.

In our study, the mean duration for resumption of day-to- day activities was 5.1 days following laparoscopic hernioplasty and 8.4 days following open hernioplasty which was statistically significant $(\mathrm{p}<0.0001)$. Rathod CM et al. reported similar results with $\mathrm{p}<0.03$ where laparoscopy group took 4.56 days and open group took 5.76 days ${ }^{[9]}$.

The strength of this study is that it compares TAPP mesh repair with Lichtenstein's open mesh repair unlike the previous studies which were TEP only or both and it includes unilateral as well as bilateral hernia. The limitation of this study is that it doesn't look into a long term follow up and it has excluded complicated hernias.

\section{Conclusion}

Our findings showed that, despite taking longer to perform, laparoscopic hernia repair had no intra-operative complications, less post-operative complications, and no recurrence. Patients had a shorter stay in the hospital, had less postoperative pain, and were able to regain their normal lives quicker. Inguinal hernia repair is one of the most difficult surgical operations, and using a laparoscopic approach will result in a better outcome and lower morbidity.

\section{Reference}

1. Amid PK. Lichtenstein's Tension Free Hernioplasty. In: Mastery of Surgery chapter 5th edition. Lippincott Williams and Wilkins's publications. 2007; 176:1932-1939.

2. Liem MS, Van Duyn EB, Van der Graaf Y, Van Vroonhoven TJ. Cola Trail Group; Recurrences after conventional anterior and laparoscopic inguinal hernia repair: A randomized comparison Ann Surg. 2003;237(1):136-41.

3. Schirmer BD, Edge SB, Dix J, Hyser MJ, Hanks JB, Jones RS. Laparoscopic cholecystectomy: Treatment of choice for symptomatic cholelithiasis Annals of surgery. 1991;213;6:665-77.

4. Neumayer L, Giobbie Hurder A, Jonasson O, Fitzgibbons R Jr, Dunlop D, Gibbs J et al. Veterans Affairs Cooperative Studies Program 456 Investigators, Open mesh versus laparoscopic mesh repair of inguinal hernias $\mathrm{N}$ Engl J Med. 2004;350(18):1819-27.

5. Lal P, Kajla RK, Chander J, Saha R, Ramteke VK. Randomized controlled study of laparoscopic total extra peritoneal versus open Lichtenstein's inguinal hernia repair Surg Endosc. 2003;17(6):850-6.

6. Colak T, Akca T, Kanik A, Aydin S. Randomized clinical trial comparing laparoscopic totally extra peritoneal approach with open mesh repair in inguinal hernia Surg Laparosc Endosc Percut Tech. 2003;13(3):191-5.

7. McCormack K, Scott NW, Go PM, Ross S, Grant AM. EU Hernia Trialists Collaboration Laparoscopic techniques versus open techniques for inguinal hernia repair. Cochrane Database Syst. Rev., 2003, 1, CD001785.

8. Hetzer FH, Hotz T, Steinke W, Schlumpf R, Decurtins M, Largiader F. Gold standard for inguinal hernia repair: Should ice or Lichtenstein? Hernia. 1999;3(3):117-20.

9. Rathod CM, Karvande R, Jena J, Ahire MD. A comparative study between laparoscopic inguinal hernia repair and open inguinal hernia repair Int. Surg. J. 2016;3:1861-7.

10. Hamza Y, Gabr E, Hammadi H, Khalil R. Four-arm randomized trial comparing laparoscopic and open hernia repairs Int. J Surg. 2010;8(1):25-8.

11. Sudarshan PB, Sundaravadanan BS, Kaarthik VP, Pabu Shankar S. Laparoscopic versus open mesh repair of unilateral inguinal hernia: a comparative study Int. Surg. J. 2017;4:921-5.

12. Neumayer L, Hurder GA, Jonasson O, Fitzgibbons R, Dunlop D, Gibbs J et al. Open mesh versus laparoscopic mesh repair of inguinal hernia $N$ Eng $J$ Med. 2004;350(18):1819-27.

13. McCormack K, Scott NW, Go PM, Ross S, Grant AM. EU Hernia Realists Collaboration. Laparoscopic techniques versus open techniques for inguinal hernia repair Cochrane Database Syst. Rev., 2003, 1, CD001785.

14. Leibl B, Daubler P, Schwarz J, Ulrich M, Bittner R. Standardised laparoscopic (TAPP) versus shouldice repair of inguinal hernia results from a prospective randomized and controlled trial Chirurg. 1995;66:895-8.

15. Barkun JS, Wexler MJ, Hinchey EJ, Thibeault D, Meakins JL. Laparoscopic versus open inguinal herniorrhaphy: preliminary results of a randomized controlled trial. Surg. 1995;118:703-10.

16. Vogt DM, Curet MJ, Pitcher DE, Martin DT, Zucker KA. Preliminary results of a prospective randomized trial of laparoscopic only versus conventional inguinal herniorrhaphy Am J Surg. 1995;169:84-90.

17. Hauters P, Meunier D, Urgyan S, Jouret JC, Janssen P, Nys JM. Prospective randomized study compar- ing laparoscopy and should ice technique in the treatment of unilateral inguinal hernia Ann Chir. 1996;50:776-81.

18. Wright DM, Kennedy A, Baxter JN, Fullarton GM, Fife LM, Sunderland GT et al. Early outcome after open versus extra peritoneal endoscopic tension-free hernioplasty: A randomized clinical trial Surgery. 1996;119:552-7. 
19. Gordon A, Gray A et al. Randomized controlled trial of laparoscopic versus open repair of inguinal hernia: Early results Brit J Med. 1995;311:981-5.

20. Horeyseck G, Roland F, Rolfes N. Tension-free repair of inguinal hernia: laparoscopic (TAPP) versus open (Lichtenstein) repair Chirurg. 1996;67(10):1036-40.

21. V Singh, U De. Laparoscopic mesh versus open mesh repair of inguinal hernia. An Experience from West Bengal, India, Int. Surg. J. 2008;20:1. 